\title{
SOLITARY VILLO ADENOMATOUS POLYP WITH CARCINOMATOUS CHANGES - RECTUM: A CASE REPORT
}

Divvya B ${ }^{1}$, M. Valluvan², Rehana Tippoo ${ }^{3}$, P. Viswanathan4, R. Baskaran ${ }^{5}$

\section{HOW TO CITE THIS ARTICLE:}

Divvya B, M. Valluvan, Rehana Tippoo, P. Viswanathan, R. Baskaran. "Solitary Villo Adenomatous Polyp with Carcinomatous Changes - Rectum: A Case Report". Journal of Evolution of Medical and Dental Sciences 2014; Vol. 3, Issue 27, July 07; Page: 7588-7594, DOI: 10.14260/jemds/2014/2941

ABSTRACT: Solitary villo-adenomatous polyp in the rectum with focal dysplastic changes involving both adenomatous and villous component is very uncommon. This 60 year old male patient presented with intermittent hematochezia. Colonoscopy did not reveal any other polypoidal lesion in the colon.

KEYWORDS: Solitary villo-adenomatous polyp - Rectum, Carcinoma-in- situ in polyp.

INTRODUCTION: A 60 years old male presented with history of hematochezia on rectal examination found to have a mass. The same was excised which morphologically and histologically proved to be a villo-adenomatous polyp with foci of dysplasia. Further examination revealed no polyp in the gastro intestinal tract.

Isolated solitary villo-adenomatous polyp in the rectum with in situ carcinoma is a rarity.

CASE SUMMARY: A 60 year old male patient presented with intermittent hematochezia. Per rectal examination revealed a mass and on proctoscopy examination, a polypoidal growth was present at $6 \mathrm{cms}$ from anal opening.

The same was excised along with the pedicle.

MACROSCOPY:A single irregular grey black, grey brown soft tissue mass measuring $6 \times 5 \times 3 \mathrm{~cm}$ resembling cauliflower with multiple surface papillary projections. Cut section showed solid grey whit to grey black with central fibro vascular core showing multiple projections on all sides.

MICROSCOPY: Section revealed a polyp with central fibrovascular core where the lining exhibited both villous and adenomatous components. The lining cells are orderly arranged. In most of the places, there is pseudo stratification. In the areas of pseudo stratification, there is varying degrees of dysplasia. Occasional mitotic figures were noticed. There is also evidence of ulceration on the surface of the polyp.

FINAL HISTOLOGICAL DIAGNOSIS: Villo-adenomatous polyp with in-situ-carcinomatous foci (involving both adenomatous and villous component).

DISCUSSION: The 60 year old male presented with an isolated pedunculated polyp in the rectum where foci of in situ carcinomatous changes were noticed both in adenomatous/ villo adenomatous component. The review of literature showed only one case of solitary villo adenomatous polyp with malignant transformation and metastatic spread ${ }^{1}$ and dysplasia has also been observed in a solitary polyp. $^{2}$ 
On colonoscopic examination and upper GI tract endoscopy no other polyp was identified. The multiple bits and sections also did not reveal any involvement of stalk. Till date patient did not have any symptoms ( 6 months follow up) and he was instructed to have long term follow up.

\section{Polyps can be:}

1. Inflammatory polyps: Non-neoplastic proliferations of either mucosa or granulation tissue due to various injuries of the colorectal epithelium like Ulcerative colitis, Crohn's disease, Ischaemic Bowel Disease and Schistosomiasis. The polyps range from finger-like projections to rounded masses. Finger-like polyps are often fused or bifid, giving rise to bizarre shapes. Bridges, through which a probe can be passed, may be formed. Variable amounts of inflammatory and granulation tissue are seen on microscopy. Cystic dilatation of glands may produce an appearance resembling the juvenile polyp. ${ }^{3}$

2. Hyperplastic (Metaplastic) polyp: Hyperplastic polyps are limited to the large intestine and appendix, with the majority occurring in the rectum and sigmoid colon. Hyperplastic polyps present as pale, sessile nodules and usually arise upon mucosal folds. Examination of the surface demonstrates the characteristically serrated or asteroid crypt openings. Histological examination reveals a slightly thickened mucosa. The crypts show little branching or budding. The cells lining the proliferative compartment in the crypt base often show enlarged, vesicular nuclei with prominent nucleoli. The nuclear membrane is delicate and there is no hyperchromatism. Mitoses may be frequent. ${ }^{3}$

\section{Hamartomatous polyps:}

a. Juvenile polyposis: Juvenile polyp is a hamatomatous polyp found mostly in the large bowel. The polyps may adopt an atypical appearance with marked papillary infolding, a relative reduction in the amount of lamina propria and absence of surface ulceration. ${ }^{3}$

b. Peutz-Jeghers polyps: Small polyps found in the colon and rectum. Such tumours show a typical tree-like branching of smooth muscle derived from the muscularis mucosae and are covered by an entirely normal colorectal epithelium. Grossly, they may mimic an adenoma. ${ }^{3}$

c. Cowden's syndrome (Multiple Hamartoma Syndrome): This rare condition is characterized by the presence of gastro intestinal, oral and cutaneous hamartomas and neoplasms of the breast and thyroid. Gastrointestinal polyps have been described as hamartomatous, and occasionally adenomatous. ${ }^{3}$

d. Bannayan-Riley-Ruvalcaba syndrome: This genetic disorder presents in childhood with macrocephaly and genital pigmentation and may develop multiple hamartomas (lipomas and haemangiomas), thyroid neoplasms and autoimmune thyroiditis, as well as gastrointestinal hamartomas. ${ }^{3}$

e. Cronkhite-Canada syndrome: A rare form of gastrointestinal polyposis presents with alopecia, skin pigmentation, nail atrophy, diarrhoea, mal absorption, protein-losing enteropathy and severe electrolyte disturbances. The mucosa is diffusely thickened with superimposed polypoid hypertrophy without ulceration. Microscopically, the epithelial tubules may show cystic dilatation and epithelial flattening. The lamina propria is expanded and oedematous. ${ }^{3}$ 
Familial adenomatous Polyposis (FAP): Familial adenomatous polyposis is characterised by hundreds of adenomas which develop throughout the colon and rectum; the risk that one or more of these will become malignant is $100 \%$. Numerous polyps of diminishing size represented by small sessile nodules on the mucosal surface are seen. Microscopic examination reveals small collections of intra mucosal tubules or even single neoplastic tubule. ${ }^{3}$

CONCLUSIONS: The patient was apparently well few months back, presented with hematochezia. Rectal examination revealed a polyp which on histology showed a villo-adenomatous polyp with carcinomatous changes involving both adenomatous and villous component. Subsequent gastro intestinal tract examination did not reveal any other polyp. On removal of the polyp patient became symptom free and as such there is no recurrence. He is on regular follow up.

\section{Polyposis coli can be classified into:}

1. Inflammatory/ Pseudopolyp

2. Hamartomatous polyp - Juvenile polyp

- Peutz-Jeghers syndrome

- Cronkhite-Canada syndrome

3. Neoplastic polyp - Benign/ Borderline

- Adenomatous

- Villous

- Villo adenoma - With or

- Without carcinoma in situ

4. Familial polyposis - Polyp can be adenomatous, villous, -Villo-adenomatous

5. Non-familial polyposis

6. Malignant-Carcinomatous polyp

- Lymphomatous polyp

Polyps can also be classified depending on the number \& location into:

- Single

- Multiple

- Involving only one anatomic site

- Involving entire gastro intestinal tract

$-$

Polyps can be - Pedunculated - with pedicle, Example. Familial polyposis coli

- Sessile, Example. Familial polyposis coli - Juvenile polyp

Polyps can be - Without complications

- With secondary complications

- Ulceration

- In situ/ dysplasia

- Malignant transformation 


\section{CASE REPORT}

\section{EQUIPMENT USED:}

Nikon Coolpix-8400.

$\mathrm{X}$-denotes the power of objective.

Stain used - (H \& E).

\section{REFERENCES:}

1. Tung-Hua L, Ming-Chang C, Hsien-Chiu T. Malignant Change Of Juvenile Polyp Of Colon A Case Report. Chin Med J 1978; 4:434-439.

2. Friedman CJ, Fechner RE. A solitary juvenile polyp with hyperplastic and adenomatous glands. Dig Dis Sci. 1982 Oct; 27(10):946-948. [PubMed]

3. Basil C. Morson, Ian M. P. Dawson. Morson and Dawson's Gastrointestinal Pathology. Third edition. 1990; 39: 584-591.

\section{MACROSCOPIC IMAGES}
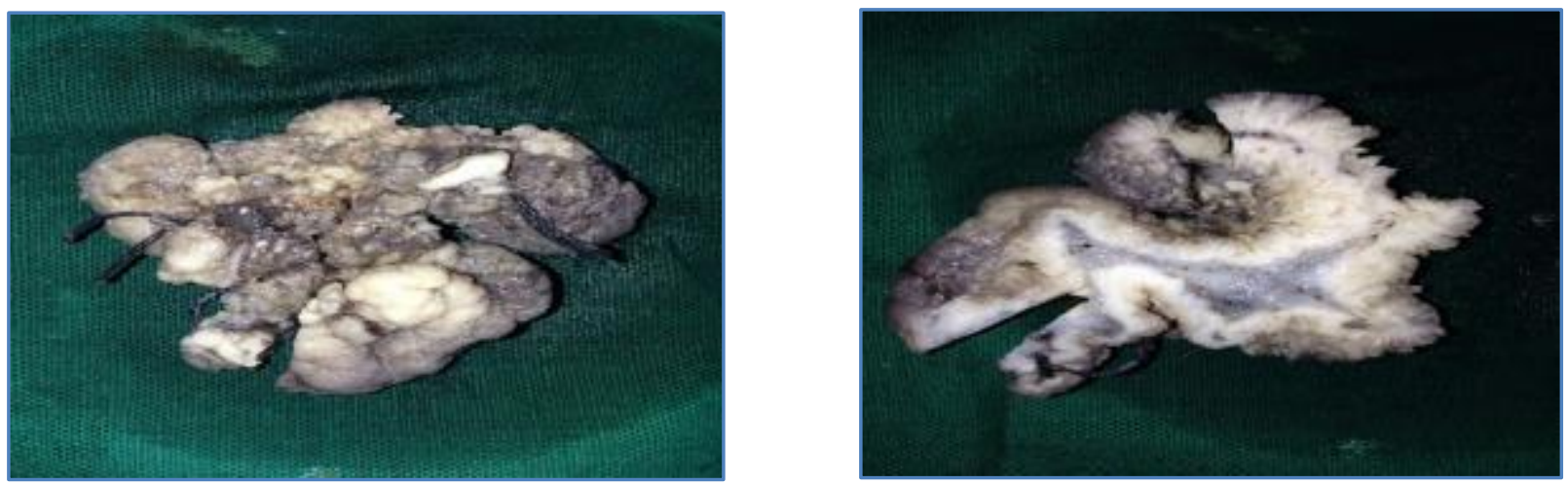

\section{MICROSCOPIC IMAGES}

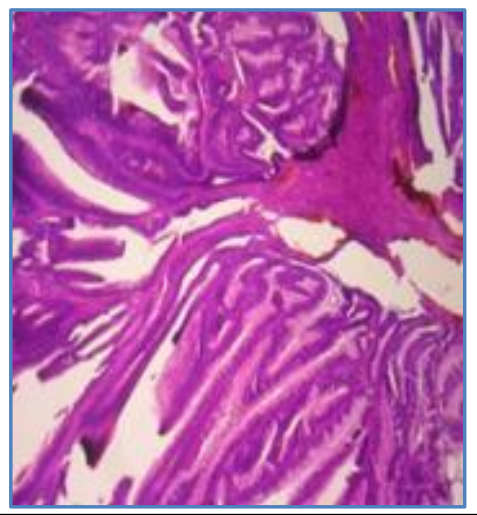

Fig. 1: H \& E stained 4x

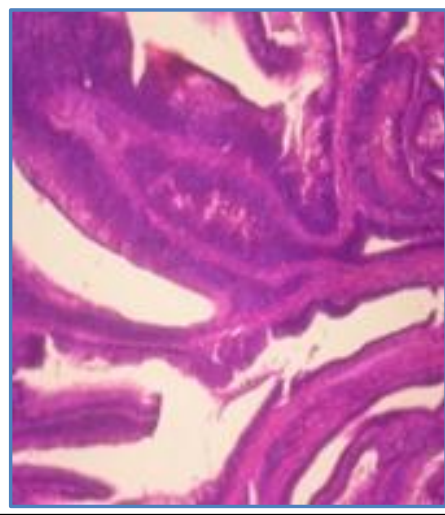

Fig. 2: H \& E stained $10 \mathrm{x}$

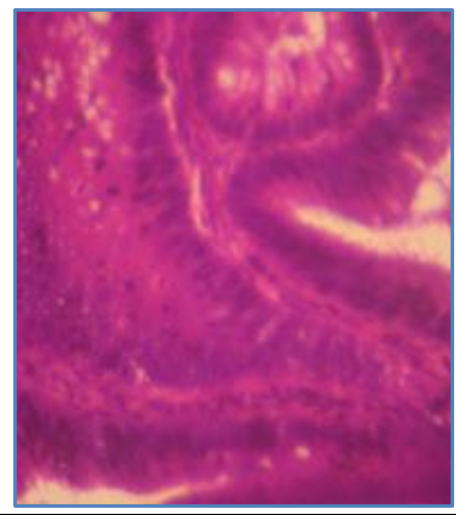

Fig. 3: H \& E stained 40x

Multiple villous processes

Fig. 3: Showing mitotic figure 


\section{CASE REPORT}

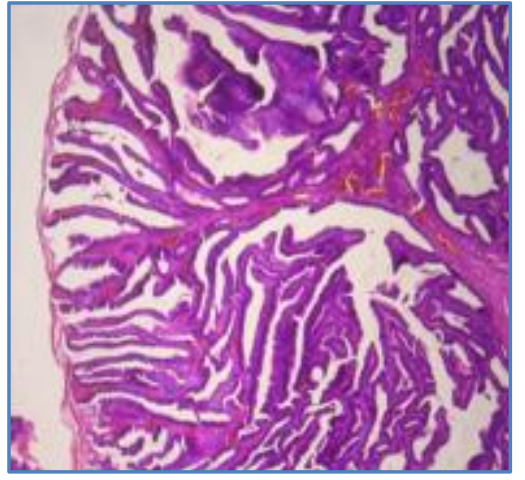

Fig. 4: H \& E stained 4x

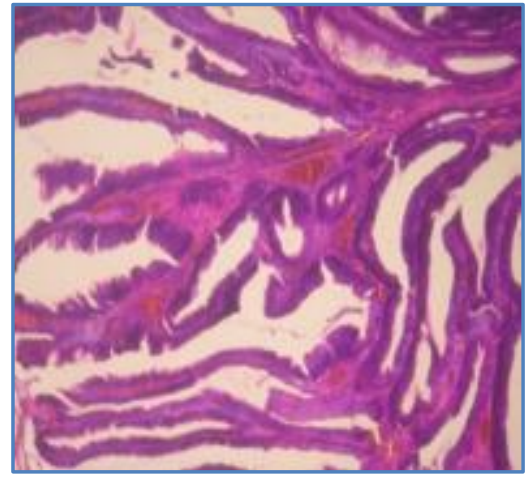

Fig. 5: H \& E stained 10x

Villous process in the form of a branch of a tree with central fibro vascular core

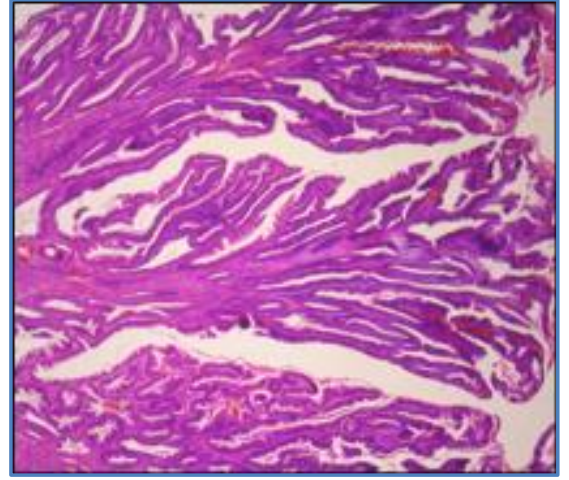

Fig. 6: H \& E stained 10x

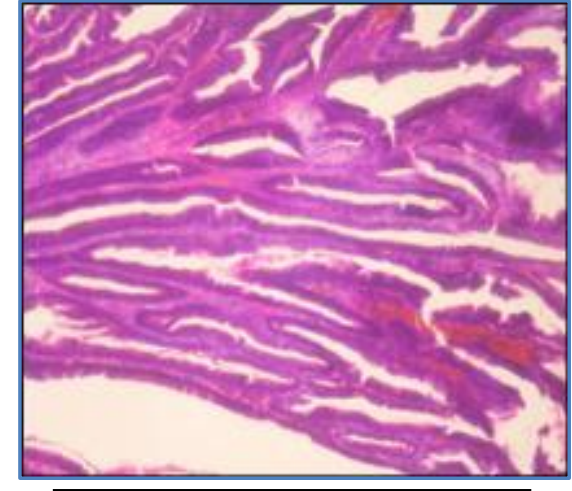

Fig. 7: H \& E stained 10x

Adeno villous component

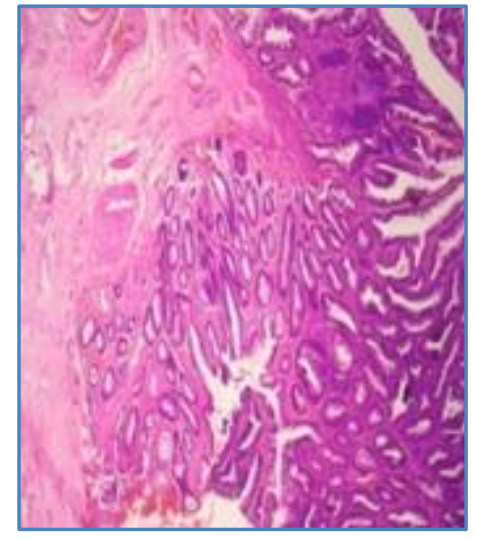

Fig. 8: H \& E stained 4x

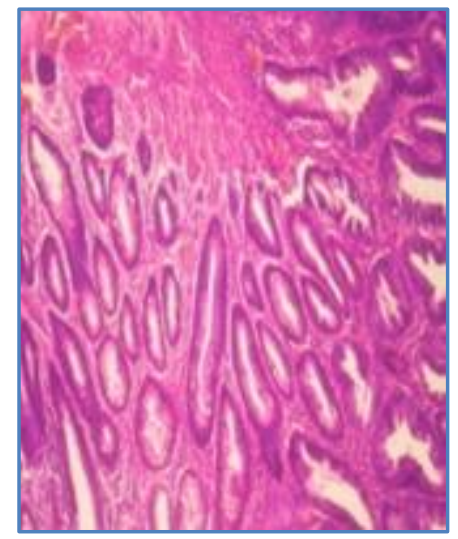

Fig. 9: H \& E stained 10x

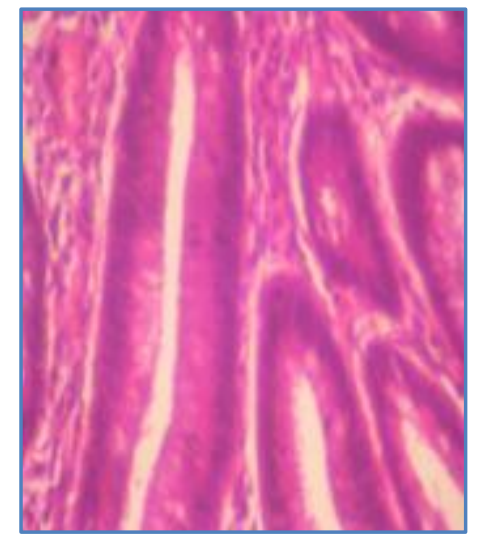

Fig. 10: H \& E stained

Close to the stalk villous and adenomatous component present 


\section{CASE REPORT}

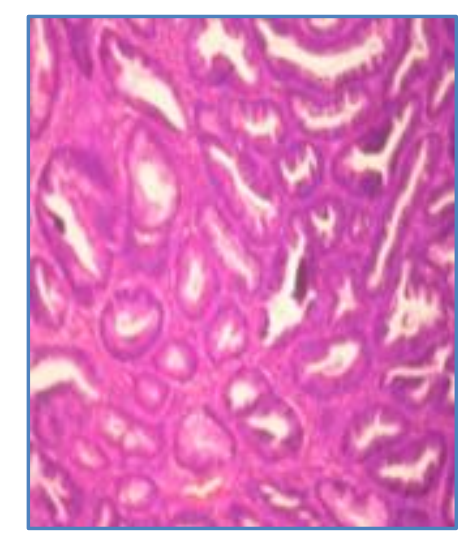

Fig. 11: H \& E stained 10x

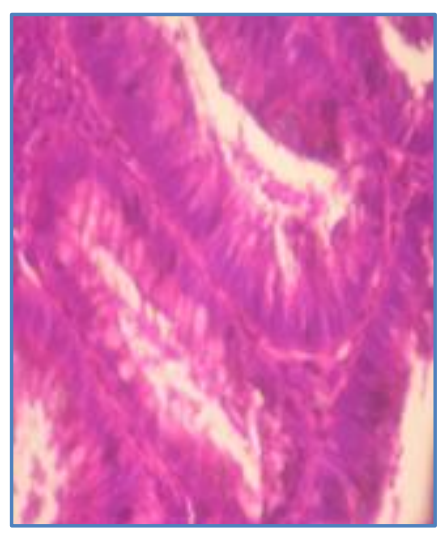

Fig. 12: H \& E stained 40x

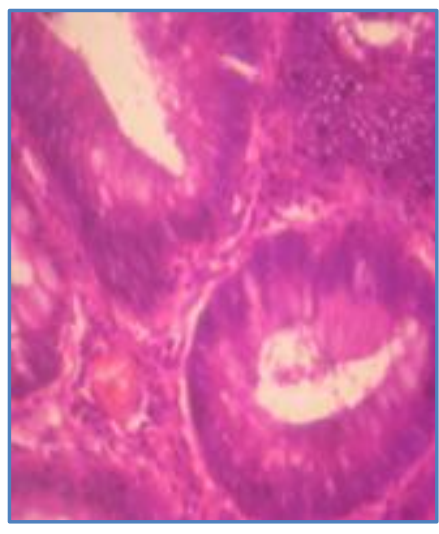

Fig. 13: H \& E stained 40x

Pseudostratification and there are scattered mitotic figures.

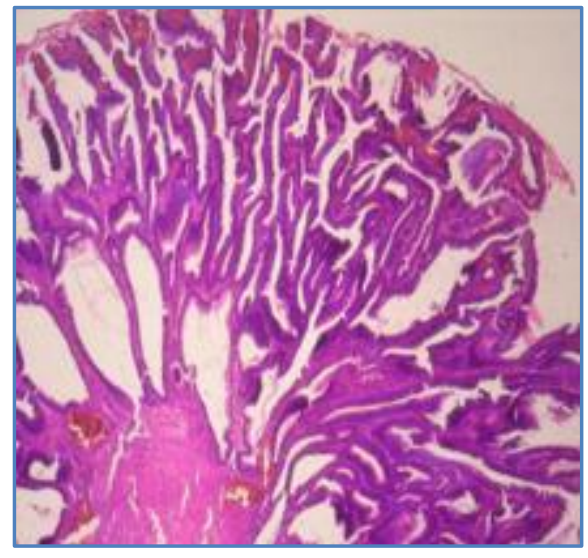

Fig. 14: H \& E stained 4x

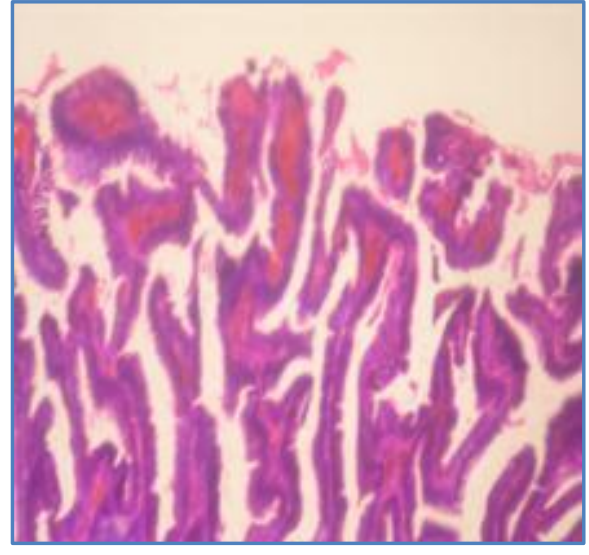

Fig. 15: H \& E stained 10x

Surface is ulcerated and congested

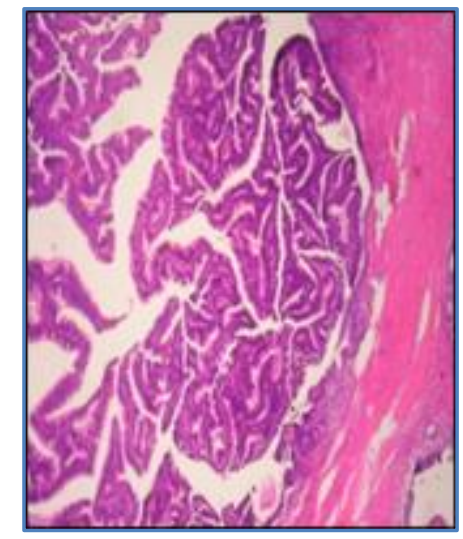

Fig. 16: H \& E stained $4 x$

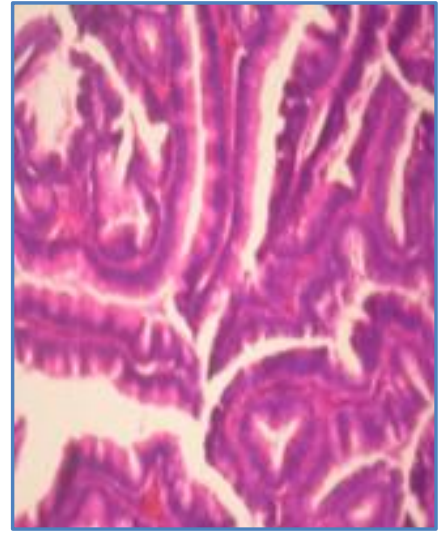

Fig. 17: H \& E stained 10x

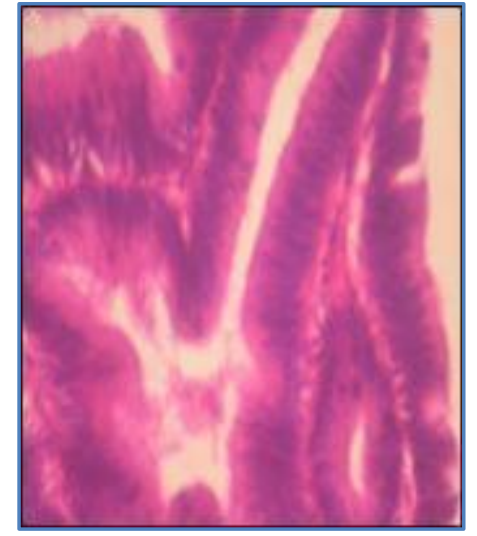

Fig. 18: H \& E stained 40x

Complex racemose type of villo-adenomatous polyp with pseudostratification and mitotic figures in both villous and adenomatous component. 


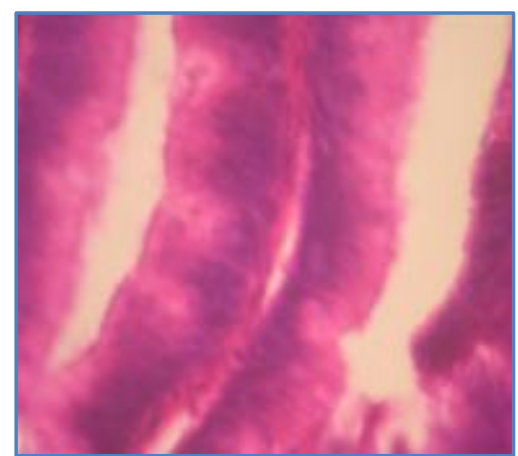

Fig. 19: H \& E stained 40x

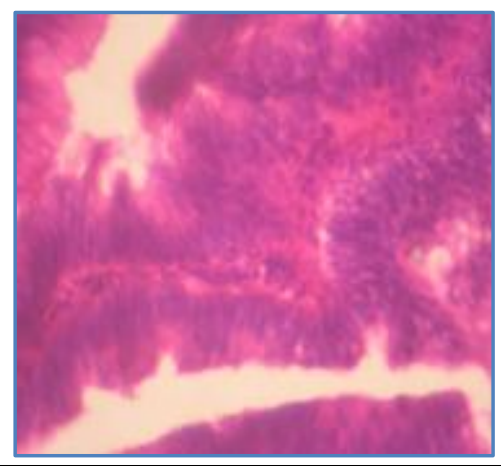

Fig. 20: H \& E stained 40x

Lining of the villous component depict vague glandular formation

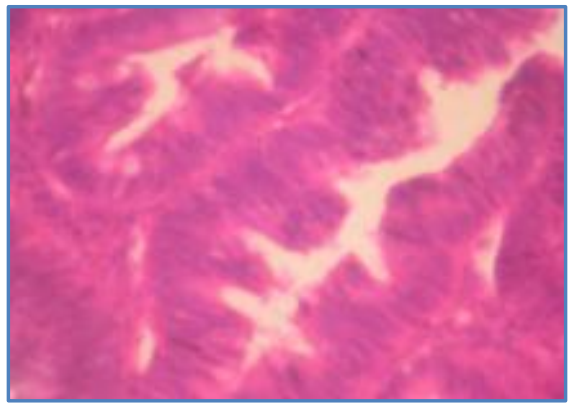

Fig. 21: H \& E stained 40x

Scattered mitotic figures present

\section{AUTHORS:}

1. Divvya B.

2. M. Valluvan

3. Rehana Tippoo

4. P. Viswanathan

5. R. Baskaran

\section{PARTICULARS OF CONTRIBUTORS:}

1. $2^{\text {nd }}$ Year Post Graduate, Department of Pathology, Rajah Muthiah Medical College, Annamalai University.

2. $2^{\text {nd }}$ Year Post Graduate, Department of Pathology, Rajah Muthiah Medical College, Annamalai University.

3. Professor, Department of Pathology, Rajah Muthiah Medical College, Annamalai University.

4. Professor, Department of Pathology, Rajah Muthiah Medical College, Annamalai University.
5. Professor, Department of Surgery, Rajah Muthiah Medical College, Annamalai University.

\section{NAME ADDRESS EMAIL ID OF THE}

\section{CORRESPONDING AUTHOR:}

Dr. P. Viswanathan,

Professor,

Department of Pathology,

Rajah Muthiah Medical College,

Annamalai University,

Chidambaram-608002,

Tamilnadu, India.

Email: drpviswanathan2013@gmail.com

Date of Submission: 20/06/2014.

Date of Peer Review: 21/06/2014.

Date of Acceptance: 30/06/2014.

Date of Publishing: 07/07/2014. 